Anuario de

Derechos Humanos 2005 


\section{Conclusiones y Recomendaciones del Comité contra la Tortura con ocasión de la presentación del Tercer Informe Periódico relativo al Estado de Chile*}

José Ignacio Escobar**
$\mathrm{L}$ os días 10 y 11 de mayo de 2004, durante las sesiones $602^{\mathrm{a}}$ y $605^{a}$, el Comité contra la Tortura (en adelante "Comité") -órgano principal de la Convención contra la Tortura y otros Tratos o Penas Inhumanos o Degradantes de 1984 (en adelante "Convención contra la Tortura" o "Convención")- revisó el tercer informe periódico del Estado de Chile (CAT/C/39/Add.5 y Corr.1), aprobando una serie de conclusiones y recomendaciones (CAT/C/CR/32/5) que son de particular importancia por una variedad de razones, inter alia, la persistencia de denuncias de casos de tortura, la incapacidad de los actores políticos para eliminar los largamente denunciados obstáculos para la realización de una justicia plena en los casos de violaciones a los derechos fundamentales en el pasado reciente, y la pronta entrada en vigencia a nivel nacional de la reforma procesal penal.

Nos proponemos realizar una breve contextualización del trabajo del Comité, para luego revisar sus conclusiones y recomendaciones someramente, concluyendo con una apreciación crítica de las medidas que se han tomado y se prevé se tomarán al interior del país, para dar efectivo cumplimiento a las mismas.

\section{Contexto}

A raíz de la fuerte presión ejercida por la Comunidad Internacional durante el régimen militar, el 30 de septiembre de 1988, Chile resolvió adoptar con reservas la Convención contra la Tortura.

La llegada de los gobiernos democráticos produjo en este ámbito un lento, aunque sostenido, movimiento para ratificar convenciones, y en lo que a la tortura concierne, retirar las reservas con las que originalmente había sido incorporada la Convención contra la Tortura al ordenamiento nacional.

En particular, en septiembre de 1991, el gobierno del Presidente Aylwin retiró las reservas relativas a los artículos $2 \mathrm{~N}^{\circ} 3^{1}$, y $3^{2}$. Posteriormente, el 22 de septiembre de 1999, se retiró la reserva relativa al párrafo primero del artículo $30^{3}$ y reconoció competencia al Comité para recibir denuncias genéricas al tenor del artículo 20. Finalmente, el 15 de marzo de 2004, el Estado de Chile terminó por reconocerle autoridad al Comité,
* Las Conclusiones y Recomendaciones del Comité contra la Tortura al Estado de Chile, están disponibles en la Sección Documentos de Interés de este Anuario.

** Abogado, Magíster en Derecho Público de la Pontificia Universidad Católica de Chile.

1 Artículo 2.3 “No podrá invocarse una orden de un funcionario superior o de una autoridad pública como justificación de la Tortura". Empero, es preciso recordar que el país aún no ha dado estricto cumplimiento al contenido de dicho numeral, en el sentido de implementar las normas internas que impidan esgrimir la obediencia debida como eximente de responsabilidad penal.

2 Este artículo establece la prohibición de expulsión, devolución o extradición de una persona a otro Estado cuando haya razones fundadas para creer que será sometida a tortura.

3 Artículo 30. "1. Las controversias que surjan entre dos o más Estados Partes con respecto a la

Este comentario, junto con el documento principal a que se refiere, están disponibles en formato digital en www.anuariocdh.uchile.cl 
interpretación o

aplicación de la presente

Convención, que no

puedan solucionarse

mediante negociaciones,

se someterán a arbitraje, a

petición de uno de ellos.

$\mathrm{Si}$ en el plazo de seis

meses contados a partir

de la fecha de

presentación de la

solicitud de arbitraje las

Partes no consiguen

ponerse de acuerdo sobre

la forma del mismo,

cualquiera de las Partes

podrá someter la

controversia a la Corte

Internacional de Justicia,

mediante una solicitud

presentada de

conformidad con el

Estatuto de la Corte.

2. Todo Estado, en el momento de la firma o ratificación de la presente

Convención o de su

adhesión a la misma,

podrá declarar que no se

considera obligado por el

párrafo 1 del presente

artículo. Los demás

Estados Partes no estarán

obligados por dicho

párrafo ante ningún

Estado Parte que haya

formulado dicha reserva.

3. Todo Estado Parte que haya formulado la reserva prevista en el párrafo 2 del presente artículo podrá retirarla en cualquier momento notificándolo al

Secretario General de las Naciones Unidas".

4 Consultada la Dirección de Derechos Humanos de la Cancillería, hasta la fecha no existe noticia de la presentación de peticiones individuales relativas a Chile en el Comité.

5 La obligación está contenida en el artículo 19 de la Convención y la periodicidad es de cuatro años.

6 Francisco Cumplido fue Ministro de Justicia de la Presidencia de Patricio Aylwin Azócar, y se le para revisar denuncias presentadas por Estados o por individuos, según lo prescrito por los artículos 21 y $22^{4}$.

A su turno, en la determinación contextual, es preciso recordar que desde la ratificación de este tratado, Chile se obligó a realizar informes periódicos ${ }^{5}$ que dieran cuenta de la realidad nacional acerca del tema de la tortura. El primero de ellos fue elaborado por el propio gobierno militar. Luego, durante el año 1990, se enviaron informes puntuales, sobresaliendo los que daban cuenta de la aprobación de las denominadas Leyes Cumplido ${ }^{6}$. Empero, el segundo informe no se evacuó sino hasta el 08 de noviembre de 1994, siendo revisado por el Comité.

El pronunciamiento del Comité que es materia de nuestro comentario, versa sobre el Tercer Informe evacuado por el Estado de Chile y, como veremos, dado el retraso en su presentación, el mismo consideró que se había proporcionado información suficiente respecto del tercer y cuarto períodos, por lo que recomendó al Estado Parte que presentase su Quinto Informe a más tardar el 29 de octubre de 2005.

Por último, sobre los aspectos formales conviene recordar que las sesiones del Comité celebradas los días 10 y 11 de mayo de 2004, fueron presenciadas por una delegación de 10 representantes del gobierno chileno, encabezada por el Representante de la Misión Permanente de Chile ante las Naciones Unidas en Ginebra. La delegación incluía a la Directora de Derechos Humanos del Ministerio de Relaciones Exteriores; al Jefe de la División de Defensa Social del Ministerio de Justicia; altos funcionarios de Carabineros y abogados de la Fiscalía Nacional, del Ministerio de Relaciones Exteriores y de Gendarmería.

Por su parte, representantes de organizaciones chilenas no gubernamentales de derechos humanos ("ONG") estuvieron presentes en las sesiones y presentaron sus informes alternativos para la consideración del Comité. Entre estas ONG se incluyen la organización sobre derechos de la mujer La Morada, el Centro de Salud Mental y Derechos Humanos, la Agrupación de Familiares de Detenidos Desaparecidos y la Corporación de Promoción y Defensa de los Derechos del Pueblo.

\section{Las Conclusiones y Recomendaciones del Comité}

Según anticipábamos, lamentando el retraso de cerca de ocho años, el Comité acogió con satisfacción el tercer informe periódico de Chile y luego de una breve introducción, repasó los aspectos positivos, los factores y dificultades que, a juicio del mismo, obstaculizan la correcta e íntegra aplicación de la Convención contra la Tortura, los motivos de preocupación, para finalizar con las recomendaciones directas.

Entre los aspectos positivos, el Comité destacó la tipificación del delito de tortura en el Código Penal, la reforma a la justicia criminal incluida la creación del Ministerio Público y la Defensoría Penal Pública, la 
derogación de la detención por sospecha, la reducción del término de la detención policial, las declaraciones de reconocimiento de nuevas competencias al Comité ya reseñadas, y la creación de la Comisión Nacional sobre Prisión Política y Tortura.

Sin perjuicio de la buena fe de los representantes del Estado, y no obstante su discutible sustento real en las políticas públicas, destaquemos el beneplácito del Comité a algunas afirmaciones realizadas por la delegación gubernamental de Chile, relativas a seguridades de que en ningún caso se condicionará a la confesión del delito la atención médica a pacientes con claras señas de haberse practicado un aborto clandestino, la afirmación de que la Convención es directamente aplicable ante los Tribunales y los supuestos avances en el proceso de ratificación del Protocolo Facultativo a la Convención contra la Tortura.

A su turno, el Comité identifica claramente un factor que dificulta y obstaculiza la aplicación efectiva de la Convención, a saber, "los arreglos constitucionales a que se llegó como parte del acuerdo político que facilitó la transición de la dictadura militar a la democracia", agregando que los mismos ponen en peligro el pleno ejercicio de determinados derechos humanos fundamentales, recordando -al tenor de lo prescrito por la Convención de Viena sobre Derecho de los Tratados- que "los condicionantes políticos internos no pueden servir de justificación para que el Estado parte incumpla las obligaciones contraídas en virtud de la Convención".

Luego, el Comité señala una serie de motivos de preocupación, inter alia, la persistencia de denuncias de malos tratos equivalentes a torturas por parte de las fuerzas de orden y seguridad y la falta de investigaciones completas e imparciales de las mismas, el amplio espectro de la jurisdicción de los tribunales militares, la ausencia de regulaciones internas específicas sobre los artículos 5 a 8 de la Convención, las malas condiciones carcelarias y la postergación de la entrada en vigor del Nuevo Código Procesal Penal en la Región Metropolitana.

Acápite separado merecen las observaciones del Comité acerca de la Comisión Nacional sobre Prisión Política y Tortura, las que reparan en el breve plazo concedido a las víctimas para inscribirse, la eventual incompatibilidad con otras formas de reparación otorgadas por el Estado $^{7}$, las limitaciones a la representación convencional de las víctimas, y el hecho de que la indemnización "austera y simbólica" (al tenor del discurso "No hay mañana sin ayer" del Presidente Lagos, que marca el punto de partida político de la Comisión Nacional sobre Prisión Política y Tortura), no equivale a una reparación "justa y adecuada", al tenor de lo dispuesto por el artículo 14 de la Convención.

Finalmente, el documento comentado se explaya en las diecisiete (17) recomendaciones que se le formulan al Estado de Chile, las que revisaremos someramente para terminar comentándolas en el acápite final. atribuyó una gran participación en la aprobación de normas favorables a la investigación y sanción de las violaciones a los derechos humanos recientes.

7 En definitiva la pensión otorgada por la Ley No19.992 (D.O. 24-122004), estableció sólo incompatibilidad con la "pensión no contributiva" que reciben los exonerados políticos. Con las demás gratificaciones de los exonerados políticos, así como con las pensiones otorgadas a propósito del Informe Rettig, no hay restricciones. 
En primer lugar, y no obstante la reciente tipificación de la tortura en el Código Penal (artículos 150 A y B), el Comité recomienda la descripción de la conducta más acorde con el artículo 1 de la Convención, en especial, en lo relativo a los propósitos de la tortura y la aquiescencia de los funcionarios públicos.

Luego sugiere al Estado la modificación de la Constitución Política de la República y la derogación de algunos cuerpos legales que impiden el libre y pleno ejercicio de los derechos fundamentales (Decreto Ley de Amnistía); la modificación de la dependencia de la policía uniformada a fin de que quede subordinada al Ministerio del Interior; la eliminación del principio de la obediencia debida del Código de Justicia Militar; la adopción de medidas que garanticen la investigación, juzgamiento y condena de las denuncias de torturas; se considere la eliminación o ampliación del término de la prescripción por este tipo de delitos; se mejoren las condiciones de los lugares de detención y se proporcione información relativa a ciertos casos paradigmáticos de torturas y sobre las denuncias interpuestas en contra de los agentes de las fuerzas de orden y seguridad en el último período democrático.

En el orden propiamente judicial, conviene destacar la sugerencia al Estado de poner en vigor, a la brevedad, la Reforma Procesal Penal en todo el territorio de la República, velando, en el marco de la misma, por introducir salvaguardias para proteger a las personas susceptibles de sufrir un nuevo trauma derivado del propio proceso judicial, en las causas sobre delitos tales como maltratos de menores y agresión sexual (victimización secundaria). Además, recomienda elaborar programas de formación a jueces, fiscales y funcionarios encargados de hacer cumplir la ley, sobre el contenido de la Convención; y también capacitar a los especialistas médicos en la identificación y documentación de la tortura. Por fin, el Comité Ilama la atención acerca de una práctica en particular, a saber, la de extraer confesiones, a efectos de enjuiciamiento, de las mujeres que buscan atención médica de emergencia como resultado de abortos clandestinos.

Finalmente, en lo concerniente a la Comisión Nacional sobre Prisión Política y Tortura, el Comité recomienda la prórroga y ampliación del mandato de la misma, a fin de permitir una mayor cobertura de las posibles víctimas, y facultar la investigación de hechos que permitan, en definitiva, el inicio de procedimientos penales contra los presuntos autores de los actos denunciados.

\section{Comentario}

Es perfectamente conocida la dificultad que los Estados afrontan a la hora de enfrentar el escrutinio internacional practicado por los órganos de supervisión. El caso de Chile respecto del Comité contra la Tortura no es la excepción. Ya mencionábamos el atraso en la elaboración del tercer informe (y es dable esperar que no se logre cumplir con la elaboración del Quinto Informe, solicitado a más tardar para octubre 
del presente año), lo que denota una falta de coordinación del aparato público en la recopilación de los datos.

Esta falta de respaldo institucional se manifiesta en la falta de una oficina de derechos humanos (o denominación equivalente), que, con la debida autoridad y presupuesto, tenga la misión de llevar adelante la coordinación de la información a proporcionar a los órganos de supervisión, así como la de construir e implementar las políticas públicas destinadas a dar efectivo y cabal cumplimiento a las recomendaciones que se formulan.

La creación de un "Instituto de Derechos Humanos" o equivalente, ha sido parte de todos los programas políticos de los gobiernos democráticamente elegidos después de 1990. Asimismo, es una recomendación que se ha repetido desde el Informe Rettig hasta el discurso "No hay mañana sin ayer", así como en el reciente Informe de la Comisión Nacional sobre Prisión Política y Tortura, sin que hasta la fecha se haya hecho realidad ${ }^{8}$.

Finalmente, no puedo dejar de mencionar que, para muchos de los que creemos en la vigencia internacional de los derechos humanos, y apostamos por derrotar la impunidad en esta área, la detención de Pinochet en Londres supuso un punto de inflexión en el desarrollo de esta disciplina, y en tal sentido, no se puede soslayar el hecho de que fue precisamente la vigencia y aplicación de esta Convención contra la Tortura, la que estuvo a la base, tanto de la petición española, como de la interesante jurisprudencia de los órganos jurisdiccionales ingleses.

Estas razones nos convocan a renovar nuestra atención crítica a la labor de los órganos internacionales de protección, pero más importante, a mantener la sana y democrática vigilancia de la gestión de nuestros gobiernos en orden a dar cabal cumplimiento y honrar los compromisos que se han asumido frente a la Comunidad Internacional en materia de Derechos Humanos.
8 De hecho, este mismo Informe dedica largos pasajes a la actitud de la comunidad internacional respecto de Chile, y los favorables efectos de esta supervisión en la disminución de la intensidad y alcance de la represión en Chile durante el gobierno militar. 